\title{
Psychosocial Determinants of Postpartum Depression and Maternal Well-Being among Postnatal Women
}

\author{
Anita Paddy1, Kenneth Asamoah-Gyimah'1, Anthony Nkyi² \\ ${ }^{1}$ Department of Education and Psychology, University of Cape Coast, Cape Coast, Ghana \\ ${ }^{2}$ Department of Guidance and Counseling, University of Cape Coast, Cape Coast, Ghana \\ Email: anita.paddy@stu.ucc.edu.gh, kasamoah-gyimah@ucc.edu.gh, ankyi@ucc.edu.gh
}

How to cite this paper: Paddy, A., Asamoah-Gyimah, K. and Nkyi, A. (2021) Psychosocial Determinants of Postpartum Depression and Maternal Well-Being among Postnatal Women. Open Journal of Psychiatry, 11, 138-159.

https://oi.org/10.4236/ojpsych.2021.113012

Received: February 21, 2021

Accepted: July 4, 2021

Published: July 7, 2021

Copyright $\odot 2021$ by author(s) and Scientific Research Publishing Inc. This work is licensed under the Creative Commons Attribution International License (CC BY 4.0).

http://creativecommons.org/licenses/by/4.0/

\begin{abstract}
Postpartum depression, a major depressive disorder, predisposes postnatal mothers to physical, social, and psychological malfunctioning. Purpose: The study aimed to identify the psychosocial determinants of postpartum depression and maternal well-being among mothers in the Accra metropolis. Materials and Method: A sample of 205 postnatal women between the ages of 15 39 years and are $4-12$ weeks old postpartum was drawn from 37 Military Hospital, Accra. Employing a sequential explanatory approach, participants were administered the Depression, Anxiety and Stress Scale (DASS-21), Multidimensional Scale of Perceived Social Support (MSPSS), Marital Adjustment Test (MAT), and the Edinburgh Postnatal Depression Scale (EPDS). Findings: The study revealed that $14.1 \%$ of postnatal women in the Accra metropolis are at risk of developing PPD. A significant model emerged, [R2 $=0.488$, $\mathrm{F}(7,197)=26.86, \rho<0.05]$ and this was predicted by anxiety, stress and marital dissatisfaction among couples. On the other hand, results from Interpretive Phenomenological Analysis (IPA) of participants' in-depth information revealed inadequate social support and dissatisfaction in marriage account for mothers' at-risk behaviour of developing PPD; which impacts on maternal well-being. Conclusion: It is concluded that PPD is patent among postnatal women and psychosocial variables contribute a significant role in their experience of mental health problems following childbirth. This, in effect, requires attention from health professionals for holistic healthcare. The implications of these outcomes are discussed concerning mental healthcare delivery, the general public, and stakeholders in the health sector.
\end{abstract}

\section{Keywords}

Psychosocial, Postpartum Depression, Maternal Health, Well-Being, Ghana 


\section{Introduction}

Many studies show that women are more prone to depression, especially when they get to the motherhood role stage [1]. Postpartum Depression (PPD), a depressive disorder, is a public health problem that has an intense effect on maternal health and well-being [2]. It begins before, or immediately after childbirth and may occur within 4 weeks to a time frame of 3 months postpartum, and the duration of its existence normally depends on how severe it may be because some depressive symptoms persist even up to a year after delivery [3] [4]. According to a 2015 report by [5], 11 - 20 percent of women who give birth each year have PPD. This phenomenon has however received little or no attention in our social environment, especially our health settings [6].

PPD, which may not have any biological underpinnings, may mostly be a result of psychosocial risk factors. These risk factors include anxiety during pregnancy, the stress in pregnancy, marital issues which may be as a result of a violent or abusive partner, and inadequate or no social support [7]-[12]. PPD can affect a mother's capacity to effectively meet her child's basic needs, which can lead to chronic, contrary effects on the child's health and well-being [13]. Mothers who suffer from PPD have changes in their diet, sleep, and activity levels and this can result in the mother being malnourished, exhausted, and overly or less energetic than usual; just as it is with general depression. When these changes occur, combined with ongoing depression and high levels of anxiety, lowers the body's immunity and its ability to fight infection. PPD has an enduring negative effect on a mother's mental health since the possibility of permanent or recurrent depression may increase which is likely to exist over five years [14] [15]. For this reason, PPD remains a major public health issue across various cultures in the world [16].

\section{Literature Review}

Depression is a product of learned helplessness. Thus, a learned expectation that events in a person's life are uncontrollable and that one cannot escape from the situation [17] and hence, give up fighting aversive events and submit to them. Other theorists have further explained that depression results from a combination of learned helplessness and an expectation that negative outcomes in one's life are unavoidable [18] [19] [20]. In his social cognitive learning theory, [21] suggests that people are shaped by an interaction between their environment, thoughts, and behaviour. Therefore, behaviour is a product of learning vicariously and through direct observation. Bandura asserts that when people begin to develop a negative self-concept, they tend to blame themselves for any misfortune that happens to them but attribute success as being caused by external factors. The negative self-concept affects their self-efficacy and hence they feel depressed whenever they are unable to achieve their desired results. Usually, emotions are felt through our thought processes and our ascriptions to events that happen around us, with postnatal mothers being inclusive. The experience 
of these emotions explains the reasons for our behaviours towards ourselves and others.

\subsection{Anxiety and PPD}

Excessive worry of mothers about the sex of their babies, whether there will be a deformity or not, and how to care for them throws them into a state of depression [22]. According to [23], anxiety occurs in up to $11 \%$ of new mothers in the forms of panic disorders which manifest as feelings of nervousness, shortness of breath, chest pain, heart palpitations, many worries or fears, among others. Anxiety among antenatal and postnatal mothers also causes them to have persistent thoughts or intrusive mental images (obsessions) related to the baby so they do things repetitively to reduce the fears and obsessions and sometimes they get a sense of distress about the obsessions. It is estimated that as many as $5 \%$ of new mothers will experience these symptoms and those mothers who experience this know that their thoughts are bizarre and are very unlikely to ever act on them [22]. The majority of studies conducted in high-income countries to examine the relationship between anxiety and PPD have reported general significant levels of anxiety being an independent predictor of PPD [24] [25] [26]. A 3-month longitudinal study of 160 women of gestational age 28 - 30 weeks conducted by [27] in Iran showed that antenatal state anxiety and trait anxiety significantly increased the risk of PPD during the first three months after childbirth but prenatal fear of childbirth was not a significant predictor of PPD.

\subsection{Stress and PPD}

Stress is explained as any challenging situation that an individual feels he/ she has inadequate resources to deal with. People who are under stress mostly find it difficult to deal with perceived challenging demands of their social environment resulting in discomfort. According to [7], stressful events experienced during pregnancy and delivery lead to PPD. However, [28] believes that it is the stress experienced after delivery and during parenting that rather leads to PPD. These stressors include daily hassles of taking care of the baby such as feeding and sleeping problems amidst constant crying of the baby, balancing work and family demands, among others. A longitudinal study involving developed and Sub-Saharan African countries revealed that the experiences of stressful life events during pregnancy and in the postpartum period were significant predictors of PPD especially among women with a history of mental health problems [29] [30] [31]. A study by [32] using in-person interviews of 4362 women and data from medical records showed that any experience of stress (acute and chronic) is significantly associated with PPD and that acute stressors occurring before pregnancy and during birth have long-lasting effects on maternal mental health.

\subsection{Marital Satisfaction and PPD}

Marital satisfaction is a mental perception that is subjective and this has a major 
impact on a woman's adjustment to what happens during and after birth. This is explained as a mother's good relationship with the father of the baby, partner availability at the time of the baby's birth, and his provision of what is perceived by her to be sufficient emotional or practical support, including high participation in infant care [33]. The extent to which a person is dissatisfied with her relationship/marriage leads to a state of distress (cognitive and emotional) and this can further cause PPD [34]. Findings from longitudinal and cross-sectional studies that have explored the relationship between marital satisfaction and the development of PPD among women in Iran, Poland, and Tirana have indicated a moderately negative statistically significant relationship between PPD and marital satisfaction, and this influences sexual satisfaction [35] [36] [37] [38]. This is an indication that PPD has a strong relationship with marital problems/ dissatisfaction. A longitudinal cohort study by [39], employing a mixed-method approach to identify the relationship between PPD and marital satisfaction revealed that women who were generally dissatisfied with the relationship between their partners in terms of difficulty with communication and poor emotional support were at high risk of developing PPD.

\subsection{Social Support and PPD}

Most studies report that little or lack of social support is the highest determinant of PPD. Social support is the provision of a social network (relationships) that is psychological and/or material and this is to equip and help an individual deal with his or her environment effectively. According to [40], social support can be instrumental, informational, and/or emotional. Lack of any of these forms of support is likely to throw a person into a depressed mood. Results from correlational, descriptive, and longitudinal studies conducted have indicated that social support is a predictive variable in determining depression in the postpartum period. That is, mothers who lived in a joint setup (extended family system) and those who received more social support from their family, friends, or spouse are less likely to suffer from PPD [41] [42] [43] [44]. A study by [45] which employed a mixed-method approach revealed that poor or limited social support from all sources resulted in stressful life events experienced among women and that significantly predicted PPD. These notwithstanding, [46] have reported no significant relationship between perceived social support from husband, family, and friends and PPD. They attributed this to the fact that perceived social support is a subjective phenomenon, and therefore depends on an individual's level of perception. Another longitudinal study by [47] to explore the role of expectations of partner support during the postpartum period confirmed that poor perceived partner support was a significant risk factor for PPD. [48] examined the relationship between social support, social networks, and symptoms of depression in a multiethnic sample of women having recently given birth. It was revealed that social support and social networks were statistically significant and independently related to PPD. 
Studies among postpartum women were mostly conducted in Low and middle-income countries (LMICs) and have reported high prevalence as compared to those conducted in developed countries. Over many years, PPD remains underdiagnosed and undertreated in LMICs [49]. Although PPD is not very common in our Ghanaian hospitals, it is reported to be quite common in LMICs. This is because psychological issues are largely overlooked in these countries. Also, during physician review, about 80 percent of women who develop PPD in later life do not fully report their experiences or how they have felt; which they believe is normal following the childbirth. Thus, physicians are unable to diagnose them [50] [51]. Psychosocial variables associated with PPD and maternal health among Ghanaian women has not been largely explored. Nonetheless, postnatal care must be holistic in its approach. It must encompass medical and psychosocial methods of management to maximize the health of the mother during this period. For this to be possible, pregnant and puerperium mothers must be screened to identify those at risk of developing the condition or those who are experiencing the condition but have not been diagnosed so that the necessary measures can be put in place.

The study would provide information for the general public especially pregnant and postnatal mothers of the existing condition and the need to be screened for the condition to identify at-risk mothers and those suffering from PPD. Again, information gathered in this study would equip healthcare providers with more knowledge on psychosocial issues that affect women during pregnancy and after birth. This will improve upon the antenatal and postnatal care services provided in Ghana and maximize maternal health.

\subsection{Research Hypotheses}

Based on the literature reviewed, the study tested the general hypothesis that psychosocial variables determine postpartum depression and maternal well-being among postnatal women in Ghana.

Five specific hypotheses tested in this regard are:

H1: The anxiety level of postnatal women will predict PPD

$\mathrm{H} 2$ : Stress experienced by postnatal women will predict PPD

H3: Marital satisfaction as experienced by postnatal women will predict PPD

H4: Social support will predict PPD of postnatal women

A research question was also asked to further explain the hypotheses that were tested.

\section{Research Question}

What psychosocial variables affect maternal well-being?

\section{Materials and Method}

This study was conducted between March and May, 2017.

\subsection{Research Design}

Collection and analysis of quantitative data on psychosocial variables preceded a 
qualitative process of data collection. The qualitative data was to explain in-depth, the identified variables that determine PPD among postnatal women in the Accra Metropolis. The descriptive survey method was adopted for the quantitative responses while interviews were conducted to collect qualitative data. Simply, the study used a sequential explanatory mixed-method design.

\subsection{Sample and Sampling Method}

The purposive sampling procedure was used to sample 205 postnatal women accessing postnatal care services at the obstetrics and gynecology, and public health departments of 37 Military Hospital. This number was obtained as women who met the inclusion criteria and agreed, to participate in the study. Ten out of the 205 women were further selected for the qualitative study because these were women who had been identified through the EPDS as those at risk of PPD based on their scores. Postnatal mothers aged 15 to 39 years, who are at least 4 weeks old and at most 12 weeks old and had no history of major or endogenous or bipolar depression were used for the study. Mothers who had lost their babies but are accessing postnatal care at the hospital and those who were unwilling to participate or demonstrated signs of being in a hurry were excluded from the study.

\subsection{Data Collection Procedure}

Ethical clearance certificates were obtained from the institutional review boards of the University of Cape Coast and the 37 Military Hospital for permission to conduct the study. This was to ensure the ethical soundness of the study. Postnatal women who were attending the postnatal care and child welfare clinic at the hospital and were willing to take part in the study were given the questionnaire to answer after giving their written consent.

\subsection{Materials}

A five-section questionnaire to obtain socio-demographic information, DASS-21, EPDS, MSPSS, and the MAT were adapted and used to obtain data for the study. A self-prepared semi-structured interview guide was also used to elicit information for the qualitative study.

Socio-Demographic Status

Biodata such as age, baby's age, educational level, marital status, and occupational status was collected. The actual age of mothers and that of their babies were obtained on a continuous level of measurement.

\subsubsection{A Measure of Anxiety and Stress}

The short form of the DASS 21 developed by [52] was used. The DASS is a single measure constructed to assess the core symptoms of depression, anxiety, and stress while maximizing discriminant validity between these constructs. This scale consists of 21 items comprising three scales of 7 items each. Items refer to 
the experience of the past week, and scores range from 0 - 3 scale $(0=\operatorname{did}$ not apply to me at all to $3=$ applied to me very much or most of the time). The anxiety scale assesses autonomic arousal, physiological hyperarousal, and the subjective feeling of fear while the stress scale items measure tension, agitation, and negative affect. Scores considered to be in the normal range are $0-4$ for depression, 0 - 3 for anxiety, and 0 - 7 for stress. Scores above these ranges indicate the degree of the problem from mild to extremely severe. The instrument is reported to have high Cronbach alpha values of Depression (range $=0.91$ to 0.97); Anxiety (range $=0.81$ to 0.92 ); and Stress (range $=0.88$ to 0.95 ) [53]. Studies have demonstrated same excellent internal consistency of the DASS scales in both the 42- and 21-item (DASS-21) versions: Depression (range $=0.91$ to 0.97 ); Anxiety (range $=0.81$ to 0.92 ); and Stress (range $=0.88$ to 0.95 ) [54] [55]. Yet, Ghanaian postpartum women were screened on this scale with $\alpha=0.88$ for DASS 21 . Cronbach alpha values for anxiety and stress were $\alpha=0.82$ and 0.72 respectively.

\subsubsection{A Measure of Marital Satisfaction}

The MAT, a 15-item questionnaire developed by [56] was used to measure the degree of satisfaction postpartum women have with their present relationship/marriage. The test contains one global adjustment question, eight questions measuring areas of possible disagreement, and six questions measuring conflict resolution, cohesion, and communication. It answers on a Likert scale ranging from 0 - 5 with 0 being always disagreed, $1=$ almost always disagree, $2=$ frequently disagree, $3=$ occasionally disagree, $4=$ almost always agree, and $5=$ always agree and total adjustment scores range from 2 to 158 points; with a score of 100 indicating mutual adjustment while an average score of 72 shows significant distress or dissatisfaction and 136 shows non-distressed individuals. Studies have shown a reliability coefficient ranged from 0.78 to 0.92 . However, Ghanaian women were tested on this scale with an overall $\alpha=0.76$, and alpha values of 0.77 and 0.83 respectively for the subscales.

\subsubsection{A Measure of Social Support}

The MSPSS developed by [57] was adopted and adapted to subjectively evaluate the sources of social support perceived by these women and how adequate it is. It is a 12 -item questionnaire that has 3 subscales that assess the perception of social support from three specific sources i.e. the family, friends, and significant others. The MSPSS is self-explanatory, simple to understand, and use, and time conserving. Items on the questionnaire are scored on a 7-point Likert scale ranging from 1 = "very strongly disagree" to 7 = "very strongly agree". The Cronbach alpha for the scale ranges from 0.92 to 0.94 for clinical samples [57] [58] [59]. Total scores on the scale range from 7 to 84 , with a higher score indicating higher levels of perceived social support and a lower score, indicates lower perceived social support. The questionnaire showed an overall reliability coefficient of 0.85 , using the specified sample; and $\alpha=0.73,0.81$, and 0.88 respectively on measures among significant other (SO), family (FAM), and friends (FRI). 


\subsubsection{A Measure of Postnatal Well-Being}

The English version of the EPDS developed by [60] was used to elicit information on the emotional and cognitive states of mothers in the postpartum period, as well as to screen them for the condition. The completed questionnaires were scored immediately. The EPDS is a self-administered, 10-item scale; each item has four possible responses from 0 to 3 , with a minimum score of 0 and a maximum of 30. The scale expresses the intensity of depressive symptoms over the preceding seven days and could be used to monitor the prevalence of depression in a community. Postnatal Ghanaian women were tested on this scale at $\alpha=$ 0.78. The EPDS had 12 as its cut-off point among the population and therefore participants who scored higher on the scale (considering scores from 16 and beyond) were engaged in informal conversations and booked for qualitative study on a scheduled date. Nine out of the 10 women who qualified for the qualitative study turned up on their scheduled appointment.

\subsection{Ethical Consideration}

Permission and ethical clearance certificates were obtained from the University of Cape Coast and $37 \mathrm{MH}$. The rights, anonymity, and confidentiality of the participants were esteemed throughout the study. Before the consent process, the type and purpose of the survey, issues of anonymity and confidentiality, voluntary participation and freedom to discontinue the interview/discussion at any stage; and absence of any known risk or benefit for participating in the study were explained. Informed written consent with the participants was taken before data collection. To preserve anonymity, all responses were presented without ascribing names or identifiable personal descriptions.

\subsection{Data Processing and Analysis}

After coding, entering, and cleaning data, a descriptive statistics test was run for all continuous variables in the questionnaire to find out the mean, minimum and maximum scores for data entered. Multiple regression analysis was used to test the research hypotheses to examine the extent to which psychosocial variables predict postpartum depression. The research question adopted a qualitative approach to give detailed information about the phenomenon. The IPA, precisely, the ideographic case-study approach was used to analyse the research question because this approach focuses on the assessment of perspectives of individual participants on issues under investigation (Vogrinc, as cited in [61]).

\section{Results and Discussion}

The study results and discussion cover the demographic characteristics of respondents, testing the study hypothesis, and answering research questions as well as other relevant findings from the study. Out of 1042 women who accessed postnatal services at 37 Military Hospital within the period of mid-March and April, 2017, the study purposively sampled 205 women.

The demographic characteristics of the respondents are shown in Table 1. 
Table 1. Demographic characteristics of respondents.

\begin{tabular}{|c|c|c|}
\hline Variable & $f$ & $\%$ \\
\hline \multicolumn{3}{|l|}{$(\mathrm{N}=205)$} \\
\hline \multicolumn{3}{|l|}{ Age of mothers (in years) } \\
\hline $15-19$ & 4 & 2.0 \\
\hline $20-24$ & 14 & 6.8 \\
\hline $25-29$ & 66 & 32.2 \\
\hline $30-34$ & 81 & 39.5 \\
\hline $35-39$ & 40 & 19.5 \\
\hline \multicolumn{3}{|l|}{ Baby's age (in weeks) } \\
\hline $4-6$ & 93 & 45.4 \\
\hline $7-9$ & 27 & 13.2 \\
\hline $10-12$ & 85 & 41.5 \\
\hline \multicolumn{3}{|l|}{ Marital status } \\
\hline Single & 13 & 6.3 \\
\hline Cohabiting & 14 & 6.8 \\
\hline Married & 174 & 84.9 \\
\hline Separated & 4 & 2.0 \\
\hline \multicolumn{3}{|l|}{ Educational Level } \\
\hline None & 6 & 2.9 \\
\hline Primary & 7 & 3.4 \\
\hline JHS & 37 & 18.0 \\
\hline SHS & 62 & 30.2 \\
\hline Tertiary & 93 & 45.4 \\
\hline \multicolumn{3}{|l|}{ Occupational status } \\
\hline Unemployed & 51 & 24.9 \\
\hline Employed & 154 & 75.1 \\
\hline Mean & SD & Range \\
\hline 30.39 & 4.57 & $15-35$ \\
\hline Baby's age & 1.19 & $4-12$ \\
\hline
\end{tabular}

Source: Field survey (2017).

\subsection{Prevalence of Postpartum Depression According to EPDS Scores}

In the present study, a sample of postnatal women accessing care at $37 \mathrm{MH}(\mathrm{N}=$ 205), the mean score of the EPDS was 5.83 with a standard deviation of 5.01 . The EPDS identified 29 women $(14.1 \%)$ to have a score equal to or above the cut-off point of 12 . These women were therefore identified as women who are likely to have postpartum depression. 


\subsection{Research Hypotheses}

Anxiety, stress, marital satisfaction, and social support of postnatal women will significantly predict postpartum depression.

To test for the hypotheses, a standard multiple regression analysis using the ENTER method was run to find out how psychosocial variables determine postpartum depression among postnatal women and the contribution of each variable to the phenomenon. A significant model emerged at 0.05 alpha level [R2 = $0.488, \mathrm{~F}(7,197)=26.86, \rho<0.05]$.

From Table 2 and Table 3, it is observed that the entire model explained about $48.8 \%$ of the variance of psychosocial determinants of PPD. The contributions of each of the psychosocial variables in explaining the variance are summarized in Table 4.

An examination of Table 4 showed that the most significant psychosocial variable that determines PPD is anxiety which is the highest predictor of psychosocial determinants at 0.05 alpha level, $[\beta=0.401, \mathrm{t}=5.832, \rho<0.05]$. This

Table 2. Model summary of regression analysis.

\begin{tabular}{ccccc}
\hline Model & $\mathrm{R}$ & R Square & Adjusted R Square & Std. Error of the Estimate \\
\hline 1 & $0.699^{\mathrm{a}}$ & 0.488 & 0.470 & 3.64545 \\
\hline
\end{tabular}

Source: Field survey (2017).

Table 3. Predictive value of psychosocial variables.

\begin{tabular}{cccccc}
\hline Model & Sum of Squares & Df & Mean Square & F & Sig. \\
\hline Regression & 2499.037 & 7 & 357.005 & $26.864^{\star}$ & $0.000^{\mathrm{b}}$ \\
Residual & 2617.987 & 197 & 13.289 & & \\
Total & 5117.024 & 204 & & & \\
\hline
\end{tabular}

${ }^{\star}$ Significant, $\mathrm{p}<0.05$. Source: Field survey (2017).

Table 4. Multiple linear regression analysis for psychosocial determinants of postpartum depression.

\begin{tabular}{cccccc}
\hline Determinants & $\mathrm{B}$ & $\mathrm{SEB}$ & $\beta$ & $\mathrm{t}$ & $\rho$ \\
\hline Anxiety & 0.638 & 0.109 & 0.401 & $5.832^{*}$ & 0.000 \\
Stress & 0.352 & 0.101 & 0.244 & $3.475^{*}$ & 0.001 \\
$\begin{array}{c}\text { Marital Satisfaction } \\
\text { Adjustment A }\end{array}$ & -0.052 & 0.048 & -0.058 & -1.080 & 0.281 \\
Adjustment B & -0.024 & 0.011 & -0.129 & $-2.080^{*}$ & 0.038 \\
Social support & & & & & \\
from significant other & -0.025 & 0.073 & -0.023 & -0.346 & 0.730 \\
from family & -0.082 & 0.045 & -0.115 & -1.844 & 0.067 \\
from friends & 0.066 & 0.035 & 0.105 & 1.878 & 0.062 \\
\hline
\end{tabular}

*Significant, $\rho<0.05$. Source: Field survey (2017). 
was followed by stress being the second highest predictor at the 0.05 alpha level $[\beta=0.244, \mathrm{t}=3.475, \rho<0.05]$ and marital adjustment among the couples was also a significant predictor $[\beta=-0.129, \mathrm{t}=-2.088, \rho<0.05]$. However, perceived social support from the individual's significant other $[\beta=-0.023, \mathrm{t}=$ $-0.345, \rho>0.05]$, individual's family $[\beta=-0.115, \mathrm{t}=-1.844, \rho>0.05]$ and support from friends $[\beta=0.105, \mathrm{t}=1.878, \rho>0.05]$ were non-significant variables in determining PPD.

Results from quantitative analysis, multiple linear regressions revealed that anxiety, stress, and marital dissatisfaction are the core predictors of PPD. These variables need to be explored further to know the extent to which they interplay to affect the mother's health and well-being in the postpartum period. Hence, this served as the basis to conduct a qualitative study.

\subsection{Research Question}

What psychosocial variables affect maternal well-being?

Interview data were recorded in audio and writing and later played to effect all corrections while achieving uniformity. From the transcribed data, three major themes emerged as psychosocial variables that affected mothers' well-being in the postpartum period. These are:

\subsubsection{Single Parenting}

One key finding that emerged as a theme from the unstructured interview, which was not previously thought to be as highly influential as the data subsequently confirmed, was the significance of single parenting in influencing mothers' well-being. Some of the participants expressed their concerns as being the only parent taking care of their babies and other children, although they were married. They become stressed out and get irritable when their babies cry and or are unable to sleep. They also reported being always sad and receiving very little or no help. This leads to quite a number of them having suicidal thoughts to end it all and that of their babies. The following quotes represent their responses:

"My husband left me when I got pregnant and never came around. I saw him a month and two weeks after I delivered and even with that, he was angry I had done a photo grid of him and my baby and posted it on Facebook. I regret everything that has gone on in my life. Sometimes, I feel like giving up my baby for adoption and then kill myself... [weeps]." (1)

"I take care of my baby alone. I $m$ not divorced but I am a second wife. I don't get to see him. I feel so tired, and most of the times I feel like fainting." (5)

"Hmmm... my husband has abandoned me and my baby and I think about my baby a lot. Due to that, the breast milk is not coming and I have to be giving her baby's food (nun 1) at this age. My baby has become very tiny. Now I feel very bad because at dawn, she tries to breastfeed and it's like nothing is coming out of the breast." (2)

\subsubsection{Financial Constraints}

One peculiar thing that ran through all the responses had to do with insufficient 
income. The majority of the participants were self-employed/ traders and expressed that the market was not good and so we're unable to satisfy their needs and that of their babies because they had little earnings. This they expressed as having a great effect on their well-being. Excerpts from their responses included:

"My income is too small; the market is not good. The money does not do anything for my children and myself." (6)

"I have spent a lot of money on my health and my income too isn't that much... as for financial challenges, it affects health." (3)

However, one participant said lack of or insufficient funds did not affect her in any way.

"I depend on my husband for income and it is not that much but my money matters cannot affect my health." (5)

\subsubsection{Marital Satisfaction}

A number of the participants reported that after birth they received less attention from their partners. Some expressed dissatisfaction with their marriage because their expectations of their partners had not been met. That is, the partners get irritable when the babies cry in the night, and also, instead of helping the mothers with carrying the babies, they would rather step out with friends. Others also expressed worry concerning too much interference with in-laws. Some of the mothers had their in-laws coming in to live with them instead of their family relations and this they describe as intrusive. This was evidenced by their quotes:

“Since I gave birth, my husband doesn't understand me and always feels $1 \mathrm{~m}$ an attention seeker... P $m$ not happy with my marriage too. I feel my husband is cheating on me... when I try to talk about issues with him he turns me down and would rather stay outside with friends especially one lady friend of his... [head down and sobs]" (8)

"I live with my mother-in-law, and she maltreats me. When it comes to the upkeep of the child, the grandmother (father's mother) helps but when it comes to me, she does not offer any support claiming that my present situation is the result of my decision to refute her advice." (1)

"My husband doesn't care about my feelings; it affects my health because it worries me too much. I m not happy with my marriage at all." (6)

The idea of being married but having to care for a child single-handedly was issues of concern to most mothers. It led to many challenges, grief, and regret. All these influenced optimum health that they are to enjoy after birth.

\section{Discussion}

Almost all women go through some changes during pregnancy and after birth and this can be explained both physiologically and psychologically. The present study is the first survey of PPD among postnatal women accessing postnatal care at 37 Military Hospital in the Accra metropolis. 


\subsection{Prevalence of Postpartum Depression}

The study indicated a high prevalence of $14.1 \%$ of PPD in a sample of Ghanaian postpartum women in Accra metropolis; which is greater than the prevalence reported among developed countries such as the United States of America (8.3\%), Canada (8\%), Brazil (10.4\%), Ukraine (8.4\%), Norway (10\%) and Sweden (13\%) [62] [63] and some Sub-Saharan African countries such as Sudan (9.2\%) and Nairobi (10.6\%) [64] [65]. However, this prevalence is similar to the 14\% rate of Saudi Arabia [65] but lesser than that of Australia (15\%), Cameroun (23.4\%), Uganda (43\%), Nigeria (22.9\%) and that of Kumasi, Ghana (22.3\%) [66] [67] [68] [69] [70].

A recent meta-analytic review of related literature by [71] and [72] reveals the general prevalence of PPD in developing countries to be $19.0 \%$ (15.5\% - 23.0\%) and $1.9 \%$ to $82.1 \%$ respectively while that of developed countries ranged from $5.2 \%$ to $74.0 \%$. The observed rate in this study, therefore, falls below the review by [71] but within the ranges of both developed and developing countries as reported by [72]. Hence, these results diffuse the assertion that PPD is more prevalent in developing countries.

\subsubsection{Anxiety and Postpartum Depression}

In the present study, results from analysis indicate a significant relationship between anxiety and PPD. That is, women who experienced anxiety in the prenatal and perinatal stages are at an increased risk of developing postpartum depression. This is in line with the study findings of [23] and [25]; which indicated that mothers who experienced all forms of anxiety during pregnancy developed PPD. Anxiety could manifest as feelings of nervousness, shortness of breath, chest pain, heart palpitations, many worries or fears, among others. From this study, it is estimated that $38.1 \%$ of the mothers are at higher risk of PPD. There is the fear of the unknown especially when one conceives. Almost every pregnant mother wants to know if her baby will be born without any defect and or will survive. These thought patterns, coupled with some negative emotions such as fear and panic, leading to a build-up of tension. Every mother perceives extreme pain associated with delivery due to existing information concerning childbirth. This increases the level of anxiety in them. Childbirth is also a matter of life and death and every pregnant woman desires to see her baby and herself survive. Yearning for a fulfilled desire comes with anxiety, as to whether the desire will be accomplished or not. However, findings from the present study are inconsistent with results from a study conducted by [22] which examined the relationship between PPD and anxiety. Thus, the mothers used in their study did not report having persistent thoughts or intrusive mental images related to their babies; which may cause them to be obsessive.

\subsubsection{Stress and Postpartum Depression}

Most of the studies conducted on PPD in developed and developing countries found a significant relationship between stress and PPD. That is, analysis from 
data in those studies indicated that stress is a significant predictor of postpartum depression and the same can be said of the present study. In a study conducted by [28] and [31], stressful events encountered during the postpartum period were associated with the development of PPD. Likewise, this study findings reveal that a quarter of the women (25.1\%) experienced stress in the postpartum period and this led to being depressed. For most of these mothers, the constant cries of their babies, intermittent sleep or sleeplessness, and the need to properly balance it with motherhood roles and their occupation, caused them a lot of distress. Moreover, some stressful life events encountered during pregnancy and delivery are carried on to the postpartum period. Stress from prolonged labour, inadequate or lack of support, financial constraints, and or burdensome occupation affects the mother's well-being from the time of conception to later time after delivery. This study's findings are also in support of findings by [29] who investigated the relationship between stressful life events experienced during pregnancy and maternal mental health during pregnancy and the postpartum period.

\subsubsection{Marital Satisfaction and Postpartum Depression}

Results from the present study have revealed a statistically significant relationship between marital satisfaction and PPD, which is consistent with findings by [36] and [38]. It can be explained that most of the women are adjusting to their marriages/relationships. Moreover, results from the qualitative study confirmed that the more an individual is not satisfied with her relationship or marriage, the more prone she is to be depressed. This may be a clue that these mothers do not have their desires and needs in the marriage met or they are not self-actualised, as postulated by the humanists' school of thought on depression. Due to the daily stressors experienced, the relationship between the couple (parents) may become very tense or even threatened by the conflict created by the mother's distress and intense needs within the relationship; and the father's struggles to know how to support his partner. It may not be that a difficult relationship causes depression; but rather, depression can cause problems in the marital relationship. Partners are much more supportive if they understand what the problem is and what they can do to help, as well as needing support and encouragement themselves otherwise they are known to be at risk of developing depression too.

In the qualitative analysis, most of the mothers complained of their dissatisfaction as a result of the possible disagreement, difficulty in resolving conflicts, cohesion and communication difficulties; and this is also supported by findings from the study conducted by [39] and that of [37], as they determined the effect of marital relationship on postnatal depression.

\subsubsection{Social Support and Postpartum Depression}

The postpartum period is an essential period where a mother is generally provided with extra support by relations. Changes that are formed in social demands, responsibilities, and relationships of a woman during this period become 
a stressful experience; and this requires extra support from family friends, and significant others to prevent any distressing situation. In the current study, results indicated a statistically non-significant relationship between perceived support from friends, significant others (partners), and families to PPD. This means that, when one perceives she receives enough social support from significant others and family during the postnatal period, her level of depression decreases. Again, analysis from qualitative data on the role of social support in developing PPD revealed that a lack of perceived support received leads to the onset of distress and depression among these mothers. On the other hand, the onset of depression, which brings changes in the mother can cause conflict in her relationships that she struggles to deal with. Significant other or family members may make efforts to enquire about or to support the mother but that may come across as critical or intrusive, especially if the mother is feeling highly sensitive or distressed. Findings from this study correspond to previous studies conducted to assess the significant role of social support in predicting women's emotional status in the postpartum period. A study by [46] in Iran reported that there is no significant relationship between perceived social support from husband, family, and friends and postpartum depression. Conversely, a study conducted by [42] in Brazil indicated a positive postpartum depression related to lack of general support from husbands, family, and friends. From the findings of this study, it can be explained that participants were not much concerned with the support they got from their friends but were keen and fretful with the other forms of support they received from significant others and partners, which they believe constitute their social network.

Results from the analysis have shown that anxiety, stress, marital dissatisfaction, inadequate or lack of social support, single parenting, and financial constraints are the psychosocial determinants of PPD and maternal well-being. This is graphically presented as Figure 1 .

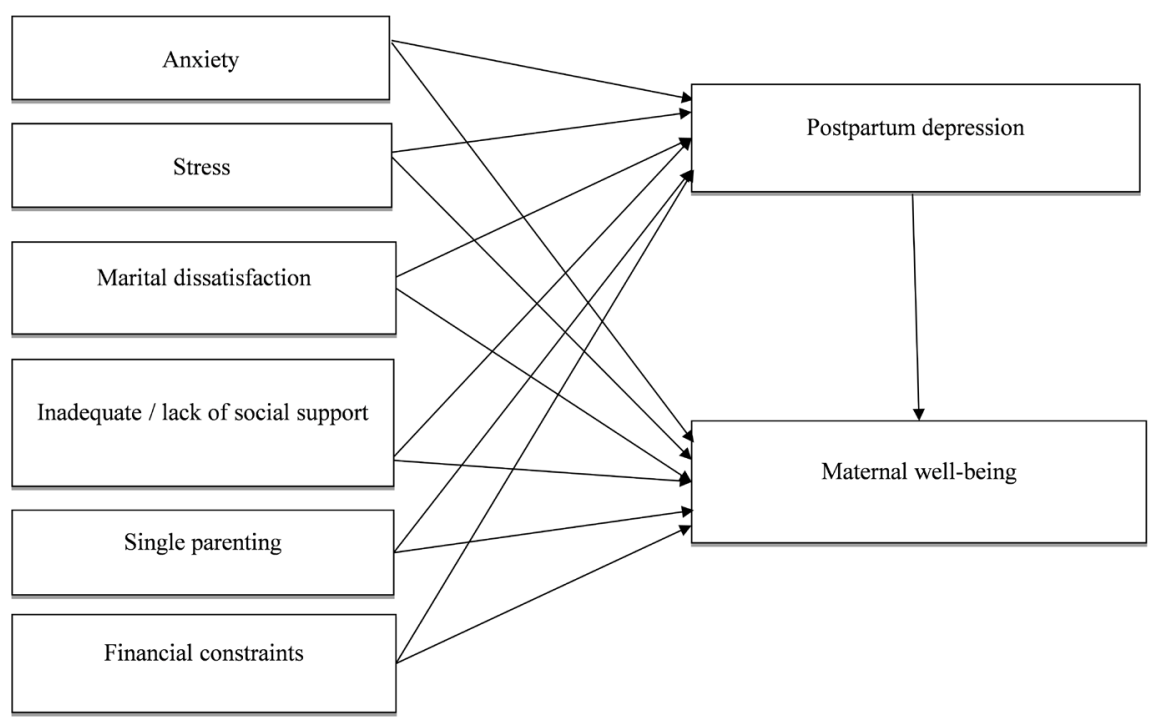

Figure 1. Psychosocial determinants of PPD and maternal well-being. 


\section{Limitation of the Study}

The main limitation of this study is that the study focused on only women between a certain age criterion, overlooking those who fall outside that criteria but maybe mothers. Again, the study lumped up new mothers together, not differentiating first-time mothers from the others. Also, the sample was obtained from only one municipality and this may affect the generalisability of the findings.

\section{Conclusions and Recommendations}

The high prevalence of PPD observed in this study is indicative of a public health issue that requires attention in prevention and possible treatment.

Although not reported in previous studies, the current study found that single parenting affected maternal well-being. Partner neglect and limited support especially in the postpartum period increased low mood and suicidal thoughts in single mothers and mothers who were married but were single-handedly taking care of their babies. It is recommended that the Ghana Health Service (GHS) under the auspices of the Ministry of Health $(\mathrm{MOH})$ should include mental health screening section in the antenatal care book to monitor mental health and well-being among mothers during the antenatal period. This will help identify women who are at risk of developing pregnancy-related or other mental illnesses, rather than focusing on those women already diagnosed with existing mental illnesses. Again, screening mothers in the antenatal period will also prevent the progression of mood disorders to the postpartum period. This will also help GHS build a good database of sufferers for monitoring and evaluation purposes.

Moreover, the general public should be educated on mental health issues as a component of health and the need to openly discuss their inapt emotions and thought patterns. The public should be alert to a wide range of social issues that affect health and well-being. This will aid in the achievement of the Third Sustainable Development Goal (SDG 3) of WHO, which seeks to ensure healthy lives and promote well-being for all ages.

\section{Suggestions for Further Research}

This study has contributed to understanding the psychosocial variables that determine postpartum depression and maternal well-being among Ghanaian postnatal women. However, there is still the need for further research to expand on the existing knowledge about the variables studied.

1) The same study should be replicated in other regions of Ghana, preferably remote areas to determine if results would be consistent with that of an urban area.

2) The 4 - 12 weeks screen for postpartum depression may have missed some women who develop PPD within six months. Given this, another study that assesses PPD among women who are beyond 12 weeks old postpartum should be 
conducted.

\section{Acknowledgements}

We appreciate the integral role played by the ethical review boards of both institutions, the efforts of family and loved ones, and study participants. Our gratitude also goes to all others who contributed in diverse ways to this study.

\section{Funding}

This study did not receive any funding.

\section{Conflicts of Interest}

Authors have no conflict of interest.

\section{References}

[1] Melinda, S. and Jaellline, J. (2016) Depression in Women: Trusted Advice for a Healthier Life. Harvard Health Publications, Boston.

[2] Elliott, S.A. (2000) Report on the Satra Bruk Workshop on Classification of Postnatal Mental disorders. Archives of Women's Mental Health, 3, 27-33.

[3] Cooper, P. (1998) Postnatal Depression. British Medical Journal, 316, 1884-1886. https://doi.org/10.1136/bmj.316.7148.1884

[4] Cox, J. (1993) A Controlled Study of the Onset, Duration, and Prevalence of Postnatal Depression. British Journal of Psychiatry, 163, 27-31. https://doi.org/10.1192/bjp.163.1.27

[5] Centre for Disease Control and Prevention [CDC] (2015) Maternal Depression. National Center for Chronic Disease Prevention and Health Promotion, Division of Population Health, Atlanta. https://www.cdc.gov/features/maternal-depression/index.html

[6] World Health Organisation (2016) Maternal Mental Health.

[7] Bernazzani, O. (1997) Psychosocial Predictors of Depressive Symptomatology Level in Postpartum Women. Journal of Affective Disorders, 46, 39-49. https://doi.org/10.1016/S0165-0327(97)00077-3

[8] Brugha, T. (1998) The Leister 500 Project: Social Support and the Development of Postnatal Depressive Symptoms: A Prospective Cohort Survey. Psychological Medicine, 28, 63-79. https://doi.org/10.1017/S0033291797005655

[9] O’Hara, M.H. (1997) The Nature of Postpartum Depressive Disorders. In: Murray, L. and Cooper, P.J., Eds., Postpartum Depression and Child Development, Guilford Press, New York, 3-31.

[10] Stewart, D.E. (2003) Postpartum Depression: Literature Review of Risk Factors and Interventions. University Health Network Women's Health Program. Toronto Public Health, Toronto.

[11] Stuchbery, M. (1998) Postnatal Depression and Social Support in Vietnamese, Arabic, and Anglo-Celtic Mothers. Social Psychiatry and Psychiatric Epidemiology, 33, 483-490. https://doi.org/10.1007/s001270050083

[12] Wenzel, A., Haugen, E.N., Jackson, L.C. and Brendle, J.R. (2005) Anxiety Symptoms and Disorders at 8 Weeks Postpartum. Journal of Anxiety Disorders, 19, 295-311. 
https://doi.org/10.1016/j.janxdis.2004.04.001

[13] Fitelson, E., Kim, S., Baker, A. and Leight, K. (2011) Treatment of Postpartum Depression: Clinical, Psychological and Pharmacological Options. International Journal of Women's Health, 3, 1-14. https://doi.org/10.2147/IJWH.S6938

[14] Pitt, B. (1973) Maternity Blues. British Journal of Psychiatry, 122, 431-433. https://doi.org/10.1192/bjp.122.4.431

[15] Wolf, A.W., De Andraca, I. and Lozoff, B. (2002) Maternal Depression in Three Latin American Samples. Social Psychiatry of Psychiatric Epidemiology, 37, 169-176. https://doi.org/10.1007/s001270200011

[16] Affonso, D.D. (2000) An International Study Exploring Levels of Postpartum Depressive Symptomatology. Journal of Psychosomatic Research, 49, 207-216. https://doi.org/10.1016/S0022-3999(00)00176-8

[17] Seligman, M.E. (1973) Fall into Helplessness. Psychology Today, 7, 43-48.

[18] Feldman, S.R. (2008) Essentials of Understanding Psychology. In: Ryan, M., Ed., The Major Psychological Disorder, 8th Edition, McGraw Hill, New York, 534-537.

[19] Kwon, P. and Laurenceau, J.P. (2002) A Longitudinal Study of the Hopelessness Theory of Depression: Testing the Diathesis-Stress Model within a Differential Reactivity and Exposure Framework. Journal of Clinical Psychology, 58, 1305-1321. https://doi.org/10.1002/jclp.10043

[20] Nemade, R., Reiss, S.N. and Dombeck, M. (2016) Cognitive Theories of Major Depression: Seligman.

[21] Bandura, A. (1977) Social Learning Theory. Prentice-Hall, Englewood Cliffs.

[22] Brandes, M., Soares, C.N. and Cohen, L.S. (2004) Postpartum Onset, Obsessive Compulsive Disorder. Archives of Women's Mental Health, 7, 99-110. https://doi.org/10.1007/s00737-003-0035-3

[23] Wisner, K.L., Peindl, K. and Hanusa, B.H. (1994) Symptomatology of Affective and Psychotic Illnesses Related to Childbearing. Journal of Affective Disorders, 30, 77-87. https://doi.org/10.1016/0165-0327(94)90034-5

[24] Austin, M.P., Tully, L. and Parker, G. (2007) Examining the Relationship between Antenatal Anxiety and Postnatal Depression. Journal of Affective Disorders, 101, 169-174. https://doi.org/10.1016/j.jad.2006.11.015

[25] Miller, R.L., Pallant, J.F. and Negri, L.M. (2006) Anxiety and Stress in the Postpartum: Is There More to Postnatal Distress than Depression? BMC Psychiatry, 6, Article No. 12. https://doi.org/10.1186/1471-244X-6-12

[26] Mohamad Yusuff, A.S., Tang, L., Binns, C.W. and Lee, A.H. (2015) Prevalence and Risk Factors for Postnatal Depression in Sabah, Malaysia: A Cohort Study. Women and Birth, 28, 25-29. https://doi.org/10.1016/j.wombi.2014.11.002

[27] Alipour, Z., Lamyian, M. and Hajizadeh, E. (2012) Anxiety and Fear of Childbirth as Predictors of Postnatal Depression in Nulliparous Women. Women and Birth, 25, e37-e43. https://doi.org/10.1016/j.wombi.2011.09.002

[28] Abidin, R. (1997) Parenting Stress Index: A Measure of the Parent-Child System. In: Woods, R.J. and Zalaquett, C.P., Eds., Evaluating Stress. A Book of Resources, Scarecrow Press, Lanham, 227-291.

[29] Alvarenga, P. and Frizzo, G.B. (2017) Stressful Life Events and Women's Mental Health during Pregnancy and the Postpartum Period. Paidéia (Ribeirão Preto), 27, 51-59. https://doi.org/10.1590/1982-43272766201707

[30] Guo, N., Bindt, C., Te Bonle, M., Appiah-Poku, J., Tomori, C., Hinz, R., et al. (2014) 
Mental Health-Related Determinants of Parenting Stress among Urban Mothers of Young Children-Results from a Birth Cohort Study in Ghana and Cote d'Ivoire. BMC Psychiatryy, 14, Article No. 156. https://doi.org/10.1186/1471-244X-14-156

[31] Venkatesh, K.K., Phipps, M.G., Triche, E.W. and Zlotnick, C. (2014) The Relationship between Parental Stress and Postpartum Depression among Adolescent Mothers Enrolled in a Randomised Controlled Prevention Trial. Maternal and Child Health Journal, 18, 1532-1539. https://doi.org/10.1007/s10995-013-1394-7

[32] Keshia, M.R. and Miles, G.T. (2015) Stress and Maternal Postpartum Depression: The Importance of Stress Type and Timing. Population Research and Policy Review, 34, 851-875. https://doi.org/10.1007/s11113-015-9368-7

[33] Burgess, A. (2011) Fathers' Roles in Perinatal Mental Health: Causes, Interactions, and Effects. New Digest, 53, 21-25.

[34] Kim, Y.-K., Hur, J.-W., Kim, K.-H., Oh, K.-S. and Shin, Y.-C. (2008) Prediction of Postpartum Depression by Sociodemographic, Obstetric and Psychological Factors: A Prospective Study. Psychiatry and Clinical Neurosciences, 62, 331-340. https://doi.org/10.1111/j.1440-1819.2008.01801.x

[35] Asghari, A., Shirdelzade, S., Saadati, M., Ghodsi, A., Bayat, R., Tabrize, E.R., et al. (2016) The Relationship of Postpartum Negative Affects with Marital Satisfaction in Parents Referred to Healthcare Centers. International Journal of Medical Research and Health Sciences, 5, 612-616.

[36] Marzieh, K.J., Azam, Z., Mahboobeh, T. and Afifeh, R.K. (2014) A study of marital Satisfaction among Non-Depressed and Depressed Mothers after Birth in Jahrom, Iran. Global Journal of Health Science, 7, 140-146. https://doi.org/10.5539/gjhs.v7n3p140

[37] Maliszewska, K., Świątkowska-Freund, M., Bidzan, M. and Preis, K. (2016) Relationship, Social Support, and Personality as Psychosocial Determinants of the Risk for Postpartum Blues. Ginekologia Polska, 87, 442-447. https://doi.org/10.5603/GP.2016.0023

[38] Meçe, D. (2013) Postpartum Depression and Marital Relationship. Academic Journal of Interdisciplinary Studies, 2, 319-323. http://dx.doi.org/10.5901/ajis.2013.v2n4p319

[39] Boyce, P. and Hickey, A. (2005) Psychosocial Risk Factors to Major Depression after Childbirth. Social Psychiatry and Psychiatric Epidemiology, 40, 605-612. https://doi.org/10.1007/s00127-005-0931-0

[40] House, J. S. and Kahn, R. L. (1985) Measures and Concepts of Social Support. In: Cohen, S. and Syme, S.L., Eds., Social Support and Health, Academic Press, New York, 83-108.

[41] Corrigan, P., Kwasky, A.N. and Groh, C.J. (2015) Social Support, Postpartum Depression, and Professional Assistance: A Survey of Mothers in the Midwestern United States. The Journal of Perinatal Education, 24, 48-60. https://doi.org/10.1891/1058-1243.24.1.48

[42] Diniz, E., Koller, S.H. and Volling, B.L. (2014) Social Support and Maternal Depression from Pregnancy to Postpartum: The Association with Positive Maternal Behaviours among Brazilian Adolescent Mothers. Journal of Early Child Development and Care, 185, 1053-1066. https://doi.org/10.1080/03004430.2014.978309

[43] Hoseini, S.S., Panaghi, L., Habibi, M., Davoodi, J. and Monajemi, M.B. (2015) The Relation between Social Support and Marital Satisfaction and Couples' Depression after the Birth of the First Child. The International Journal of Indian Psychology, 3, 
5-14.

[44] Kazmi, S.F., Khan, M., Tahir, R., Dil, S. and Khan, A.M. (2013) Relationship between Social Support and Postpartum Depression. Annual Pakistanian Institute of Medical Sciences, 9, 191-194.

[45] Reid, K.M. and Miles, G.T. (2012) Examining Postpartum Depression from a StressProcess Perspective: The Importance of Stress Type and Timing. Annual Meeting of the Population Association of America, New York, March 2012, Poster Presentation/New York.

[46] Nazari, M., Ghasemi, S., Vafaei, H. and Fararouei, M. (2015) The Perceived Social Support and Its Relationship with Some of the Demographic Characteristics in Primigravida Pregnant Women. International Journal of Nursing and Midwifery, 7, 141145. https://doi.org/10.5897/IJNM2015.0186

[47] Gremigni, P., Mariani, L., Marracino, V., Tranquilli, A.L. and Turi, A. (2011) Partner Support and Postpartum Depressive Symptoms. Journal of Psychosomatic Obstetrics \& Gynecology, 32, 135-140. https://doi.org/10.3109/0167482X.2011.589017

[48] Surkan, P.J., Peterson, K.E., Hughes, M.D. and Gottlieb, B.R. (2006) The Role of Social Networks and Support in Postpartum Women's Depression: A Multi-Ethnic Urban Sample. Maternal and Child Health Journal, 10, 375-383.

https://doi.org/10.1007/s10995-005-0056-9

[49] World Health Organization (2008) Maternal Mental Health and Child Health and Development in Low and Middle-Income Countries. Report of the WHO-UNFPA Meeting, Geneva.

[50] Halbreich, U. and Karkun, S. (2006) Cross-Cultural and Social Diversity of Prevalence of Postpartum Depression and Depressive Symptoms. Journal of Affective Disorder, 91, 97-111. https://doi.org/10.1016/j.jad.2005.12.051

[51] Kelly, R.H., Russo, J. and Katon, W. (2001) Somatic Complaints among Pregnant Women Care or in Obstetrics: Normal Pregnancy or Depressive and Anxiety Symptom Amplification Revisited? General Hospital Psychiatry, 23, 107-113. https://doi.org/10.1016/S0163-8343(01)00129-3

[52] Lovibond, S.H. and Lovibond, P.F. (1995) Manual for the Depression Anxiety \& Stress Scales. Psychology Foundation, Sydney.

https://doi.apa.org/doi/10.1037/t01004-000

[53] Antony, M., Bieling, P.J., Cox, B.J., Enns, M.W. and Swinson, R.P. (1998) Psychometric Properties of the 42-Item and 21-Item Versions of the Depression Anxiety Stress Scales in Clinical Groups and Community a Sample. Psychological Assessment, 10, 176-181. https://doi.apa.org/doi/10.1037/1040-3590.10.2.176

[54] Crawford, J.R. and Henry, J.D. (2003) The Depression Anxiety Stress Scales (DASS): Normative Data and Latent Structure in a Large Non-Clinical Sample. British Journal of Clinical Psychology, 42, 111-131. https://doi.org/10.1348/014466503321903544

[55] Clara, I.P., Cox, B.J. and Enns, M.W. (2001) Confirmatory Factor Analysis of the Depression Anxiety Stress Scales in Depressed and Anxious Patients. Journal of Psychopathology and Behavioral Assessment, 23, 61-67. https://doi.org/10.1023/A:1011095624717

[56] Locke, H.J. and Wallace, K.M. (1959) Short Marital Adjustment and Prediction Tests: Their Reliability and Validity. Marriage and Family Living, 21, 251-255. https://doi.org/10.2307/348022

[57] Zimet, G.D., Dahlem, N.W., Zimet, S.G. and Farley, G.K. (1988) The Multidimen- 
sional Scale of Perceived Social Support. Journal of Personality Assessment, 52, 30-41. https://doi.org/10.1207/s15327752jpa5201_2

[58] Clara, P.I., Cox, B.J., Enns, M.W., Murray, L.T. and Torgrude, L.J. (2003) Confirmatory Factor Analysis of the Multidimensional Scale of Perceived Social Support in Clinically Distressed and Student Samples. Journal of Personality Assessment, 81, 265-270. https://doi.org/10.1207/S15327752JPA8103 09

[59] Zimet, G.D., Powell, S.S., Farley, G.K., Werkman, S. and Berkoff, K.A. (1990) Psychometric Characteristics of the Multidimensional Scale of Perceived Social Support. Journal of Personality Assessment, 55, 610-617. https://doi.org/10.1080/00223891.1990.9674095

[60] Cox, J.L, Holden, J.M. and Sagovsky, R. (1987) Detection of Postnatal Depression: Development of the 10-Item Edinburgh Postnatal Depression Scale. British Journal of Psychiatry, 150, 782-786. https://doi.org/10.1192/bjp.150.6.782

[61] Smith, J.A. and Osborn, M. (2015) Interpretive Phenomenological Analysis as a Useful Methodology for Research on the Lived Experiences of Pain. British Journal of Pain, 9, 41-42. https://doi.org/10.1177\%2F2049463714541642

[62] Lanes, A., Kuk, J.L. and Tamim, H. (2011) Prevalence and Characteristics of Postpartum Depression Symptomatology among Canadian Women: A Cross-Sectional Study. BMC Public Health, 11, Article No. 302. https://doi.org/10.1186/1471-2458-11-302

[63] Kessler, R.C., Birnbaum, H.G., Shahly, V., Bromet, E., Hwang, I., McLaughlin, K. A., et al. (2010) Age Differences in the Prevalence and Co-Morbidity of DSM-IV Major Depressive Episodes: Results from the WHO World Mental Health Survey Initiative. Depression and Anxiety, 27, 351-364. https://doi.org/10.1002/da.20634

[64] Khalifa, D.S, Glavin, K., Bjertness, E. and Lien, L. (2015) Postnatal Depression among Sudanese Women: Prevalence and Validation of the Edinburgh Postnatal Depression Scale at 3 Months Postpartum. International Journal of Women's Health, 7, 677-684. https://doi.org/10.2147/IJWH.S81401

[65] Al-Modayfer, O., Alatiq, Y., Khair, O. and Abdelkawi, S. (2015) Postpartum Depression and Related Risk Factors among Saudi Females. International Journal of Culture and Mental Health, 8, 316-324. https://doi.org/10.1080/17542863.2014.999691

[66] Chinawa, J.M., Odetunde, I.O., Ndu, I.K., Ezugwu, E.C., Aniwada, E.C. and Chinawa, A.T. (2016) Postpartum Depression among Mothers as Seen in Hospitals in Enugu, South-East Nigeria: An Undocumented Issue. The Pan African Medical Journal, 23, Article No. 180. https://doi.org/10.11604/pamj.2016.23.180.8244

[67] Adama, N., Foumane, P., Olen, J., Dohbit, J., Meka, E. and Mboudou, E. (2015) Prevalence and Risk Factors of Postpartum Depression in Yaounde, Cameroon. Open Journal of Obstetrics and Gynecology, 5, 608-617. https://doi.org/10.4236/ojog.2015.511086

[68] Afriyie, A.B. (2015) Risk Factors Influencing Postpartum Depression among Women Attending the Postnatal Clinic at Komfo Anokye Teaching Hospital, Kumasi, Ghana. B.Sc., Human Biology, MBCHB, Kwame Nkrumah University of Science \& Technology, Kumasi.

[69] Kakyo, T.A., Muliira, J.K., Mbalinda, S.N. and Muliira, R. (2012) Factors Associated with Depressive Symptoms among Postpartum Mothers in a Rural District in Uganda. Midwifery, 28, 374-379. https://doi.org/10.1016/j.midw.2011.05.001

[70] Glavin, K., Smith, L. and Sørum, R. (2009) Prevalence of Postpartum Depression in Two Municipalities in Norway. Scandinavian Journal of Caring Sciences, 23, 705-710. 
https://doi.org/10.1111/j.1471-6712.2008.00667.x

[71] Gelaye, B., Rondon, M., Araya, R. and Williams, M.A. (2016) Epidemiology of Maternal Depression, Risk Factors, and Child Outcomes in Low-Income and MiddleIncome Countries. Lancet Psychiatry, 3, 973-982. https://doi.org/10.1016/S2215-0366(16)30284-X

[72] Norhayati, M.N., Nik Hazlina, N.H., Asrenee, A.R. and Wan Emilin, W.M.A. (2015) Magnitude and Risk Factors for Postpartum Symptoms: A Literature Review. Jour nal of Affective Disorders, 175, 34-52. https://doi.org/10.1016/j.jad.2014.12.041 